\title{
REVIEW
}

\section{Hip Osteoarthritis: Etiopathogenesis and Implications for Management}

Nicholas J. Murphy · Jillian P. Eyles · David J. Hunter

Received: June 30, 2016 / Published online: September 26, 2016

(C) The Author(s) 2016. This article is published with open access at Springerlink.com

\begin{abstract}
Highly prevalent among the elderly, hip osteoarthritis (OA) carries a heavy burden of disease. Guidelines for the management of hip $\mathrm{OA}$ are often extrapolated from knee OA research, despite clear differences in the etiopathogenesis and response to treatments of $\mathrm{OA}$ at these sites. We propose that hip OA

of the condition's etiopathogenesis. The evidence for currently adopted management strategies is considered, especially those approaches that may have disease-modifying potential. We propose that shifting the focus of hip OA research and public health intervention to primary prevention and early detection may greatly improve the current management paradigm.
\end{abstract} requires specific attention separate from other OA phenotypes. Our understanding of the etiopathogenesis of hip OA has seen significant advance over the last 15 years, since Ganz and colleagues proposed femoroacetabular impingement (FAI) as an important etiological factor. This narrative review summarizes the current understanding of the etiopathogenesis of hip OA and identifies areas requiring further research. Therapeutic approaches for hip OA are considered in light

Enhanced content To view enhanced content for this article go to http://www.medengine.com/Redeem/ DFD6F0602CC1D0AD.

N. J. Murphy · J. P. Eyles · D. J. Hunter $(\square)$ Department of Rheumatology, Royal North Shore Hospital and Northern Clinical School, University of Sydney, Reserve Road, St Leonards, Sydney, NSW 2065, Australia e-mail: David.Hunter@sydney.edu.au
Keywords: Etiology; FAI; Femoroacetabular impingement; Hip; Management; Osteoarthritis; Risk factors; Rheumatology; Therapy

\section{INTRODUCTION}

Hip osteoarthritis (OA) is among the most prevalent and disabling conditions affecting the elderly. There is an estimated $25 \%$ lifetime risk of symptomatic hip OA in people who live to age 85 [1], and almost $10 \%$ lifetime risk of undergoing a total hip replacement for end-stage OA [2]. However research on hip OA has generally languished behind knee OA-specific research, possibly owing to the even higher prevalence of 
knee OA [3] and the greater ease with which the knee joint can be imaged [4] and accessed for clinical interventions. Clinical guidelines often combine hip and knee OA [5-7], at times extrapolating from knee $\mathrm{OA}$ research to make recommendations for the management of hip $\mathrm{OA}$. This is despite the growing consensus that $\mathrm{OA}$ is not a single disease affecting the joints, but rather a number of distinct conditions, each with unique etiological factors and possible treatments, which share a common final pathway [8-10]. This review will focus on the joint-specific etiopathogenesis of hip OA and its implications for future management approaches. Perhaps the greatest potential for improved management lies in shifting the management paradigm from palliation of end-stage disease, to instead focus on the earliest stages of the condition's pathogenesis.

\section{METHODS}

For this narrative review, Medline was searched using various combinations of terms pertinent to the topic, including "hip osteoarthritis", "etiology", "femoroacetabular impingement", "pathogenesis", "risk factors", "epidemiology", and "management". Key articles of importance were selected through this process as well as from the authors' prior knowledge of the literature; the reference lists of these key articles were also used to select additional references of relevance for our review. This article is based on previously conducted studies and does not involve any new studies of human or animal subjects performed by any of the authors.

\section{DIAGNOSIS OF HIP OA}

The American College of Rheumatology have established criteria that are commonly used for the diagnosis of hip OA in clinical practice (Table 1) [11]. It is often possible to diagnose hip OA on the basis of clinical presentation alone, although radiographic investigation can be useful to confirm the diagnosis and to monitor disease progression.

The most common system for measuring radiographic OA severity is the Kellgren and Lawrence (K\&L) grade, which uses a five-point scale between 0 and 4 , with grades of 2 and higher indicating radiographic OA [12]. Higher $\mathrm{K} \& \mathrm{~L}$ grades demonstrate increased joint space narrowing, increased osteophyte involvement, and subchondral sclerosis. Symptomatic disease progression can also be monitored with patient-reported outcomes such as the Oxford Hip Score. There is substantial discord between symptoms and radiographic findings; a high proportion of those with radiographic features of hip OA are asymptomatic, and a similarly high proportion of those with symptoms suggestive of hip OA lack radiographic evidence [13]. Consideration of both clinical and radiographic severity is relevant to direct clinical management.

\section{PREVALENCE OF HIP OA}

The age-standardized prevalence of symptomatic radiographic hip OA has varied from $1 \%$ to $10 \%$ in large population-based prevalence surveys [14-18]. These marked differences in prevalence can be attributed to differences in risk factor profiles between the populations sampled. The two largest USA-based prevalence surveys, the Johnston County Osteoarthritis Project [18] and Framingham Osteoarthritis Study [16], found prevalence rates of $10 \%$ and $4.2 \%$, respectively. The higher prevalence in the Johnston County Project is likely due to this rural population 
Table 1 American College of Rheumatology criteria for the diagnosis of hip osteoarthritis [11]

\begin{tabular}{lll}
\hline Clinical criteria $\mathbf{A}$ & Clinical criteria $\mathbf{B}$ & Clinical plus radiographic criteria \\
\hline Hip pain; AND & Hip pain; AND & Hip pain; AND any 2 of the following: \\
$\begin{array}{l}\text { Hip internal rotation } \\
<15^{\circ} ; \text { AND }\end{array}$ & Pain with internal hip rotation; AND & ESR $<20 \mathrm{~mm} / \mathrm{h}$ \\
$\begin{array}{l}\text { ESR } \leq 45 \mathrm{~mm} / \mathrm{h} \text { or hip } \\
\begin{array}{l}\text { flexion } \leq 115^{\circ} \text { if ESR } \\
\text { unavailable }\end{array}\end{array}$ & Overning stiffness of hip $\leq 60 \mathrm{~min}$; AND & $\begin{array}{c}\text { Radiographic femoral and/or acetabular } \\
\text { osteophytes }\end{array}$ \\
\hline
\end{tabular}

ESR erythrocyte sedimentation rate

containing a much higher proportion of farmers and African Americans, both of which are independent risk factors for hip OA [18]. In contrast, the Framingham Osteoarthritis Study included an urban, mostly Caucasian population. The prevalence of hip OA was $1 \%$ in the Beijing Osteoarthritis Study, reflecting greatly reduced risk of hip OA in Asian ethnicities [14]. It is worth noting that the prevalence of hip OA in each of these studies is much higher when hip OA is defined using either radiographic or symptomatic criteria in isolation [14-18].

\section{PATHOGENESIS OF EARLY OA}

Although this review is written on the premise that hip OA has a unique etiology and epidemiology requiring specific attention, it is instructive to consider the elements common to the pathogenesis of all OA-affected joints. Physiological biomechanical loading has long been recognized as necessary for joint tissue homeostasis [19, 20]. However in joints undergoing osteoarthritic change, pathological biomechanical stress disrupts the homeostatic equilibrium between joint tissue synthesis and degradation, eventually resulting in end-stage OA [21]. Pathological biomechanical stress is caused by the presence of risk factors both at the joint and person levels, and plays a central role in initiating and driving the pathogenesis of $\mathrm{OA}$ [22-24]. Particular biomechanical patterns have been implicated in this process. Repetitive shear stress at the articular surface has been associated with cellular and molecular changes involved in the pathogenesis of $\mathrm{OA}$, including decreased expression of type II collagen and proteoglycans in articular cartilage, increased release of pro-inflammatory mediators, and increased apoptotic cellular changes [22].

The cellular and molecular changes that accompany altered biomechanical loading in the pathogenesis of early $\mathrm{OA}$ are the subject of a large body of research. The osteochondral junction, a region encompassing the subchondral bone and articular cartilage, has been heavily implicated. The subchondral bone and articular cartilage act as a single functional unit, responding in a coordinated fashion to altered biomechanical loading [25-27]. In response to altered joint biomechanics, subchondral bone remodelling with accelerated levels of subchondral bone turnover occurs. This manifests as increased porosity and thinning of the subchondral bone plate and trabecular bone. Simultaneously, cartilage microdamage occurs in the form of microcracks, which span the thickness of the non-calcified, tidemark and calcified cartilage regions and subchondral bone. These microcracks facilitate increased vascularization 
and the bidirectional passage of important cytokines and growth factors throughout the osteochondral junction, thus connecting the cartilage and subchondral bone biochemically as well as mechanically [25-27]. The precise signalling molecules involved in the biochemical cross talk between articular cartilage and subchondral bone have not yet been fully elucidated. It is hypothesized that stressed articular cartilage releases pro-inflammatory cytokines and osteoclast-stimulating molecules that reach the subchondral bone to affect subchondral bone remodelling $[25,28]$ Likewise, pro-inflammatory signalling molecules released by osteoblasts in subchondral bone are thought to reach articular cartilage where they promote cartilage breakdown [25, 29]. Synovitis with lymphocytic infiltration has also been identified in early-stage $\mathrm{OA}$ [30], underlining the whole-joint nature of the disease's pathogenesis even in its earliest stages. Increased understanding of the pathogenesis of early OA is important, as the potential for arresting disease course before extensive joint damage has occurred is likely greater at this stage.

\section{ETIOLOGY AND RISK FACTORS FOR HIP OA}

Risk factors for hip OA can be split into those at the joint level and those at the whole person level, with the caveat that these two categories of risk factors do not exist independently of one another. Rather, joint level risk factors may be considered the etiological basis for the development of hip OA, whereas whole person level risk factors contribute to the development of hip OA indirectly, by increasing susceptibility to joint level risk factors (Fig. 1).

\section{Joint Level Risk Factors}

\section{Joint Morphology}

In hip OA, the most significant factor that has emerged as responsible for the onset of the cascade described above is the presence of abnormal hip joint morphology, be it subtle or obvious, which is believed to lead to pathological loading patterns that produce shear stresses on the hip joint over time [31]. Although obvious hip joint deformity such as in severe developmental dysplasia of the hip (DDH) has long been recognized as a cause of early-onset secondary hip OA [32-34], it was originally thought that the majority of hip OA was idiopathic [35]. Some decades ago it was first proposed that almost all hip $\mathrm{OA}$ is secondary to subtle forms of joint deformity [36]; however, it is only in the last 15 years that this idea has gained traction $[37,38]$. It has been proposed that joint morphology abnormalities exist on a continuous spectrum, with worse abnormalities such as in severe femoroacetabular impingement (FAI) or DDH associated with high risk of early OA onset, and more subtle morphological abnormalities associated with late-onset, so-called primary OA [31].

\section{Developmental Dysplasia of the Hip}

A shallow and oftentimes maloriented acetabulum causes decreased femoroacetabular contact surface area in DDH. This results in the distribution of shear forces anterosuperiorly in the hip joint onto the acetabular rim (Fig. 2) [39]. Over time these forces cause degeneration of the acetabular labrum anterosuperiorly and degeneration of the articular cartilage via its response to shear stress described earlier. Eventually whole joint failure occurs with the onset of hip OA [40]; in severe dysplasia this 


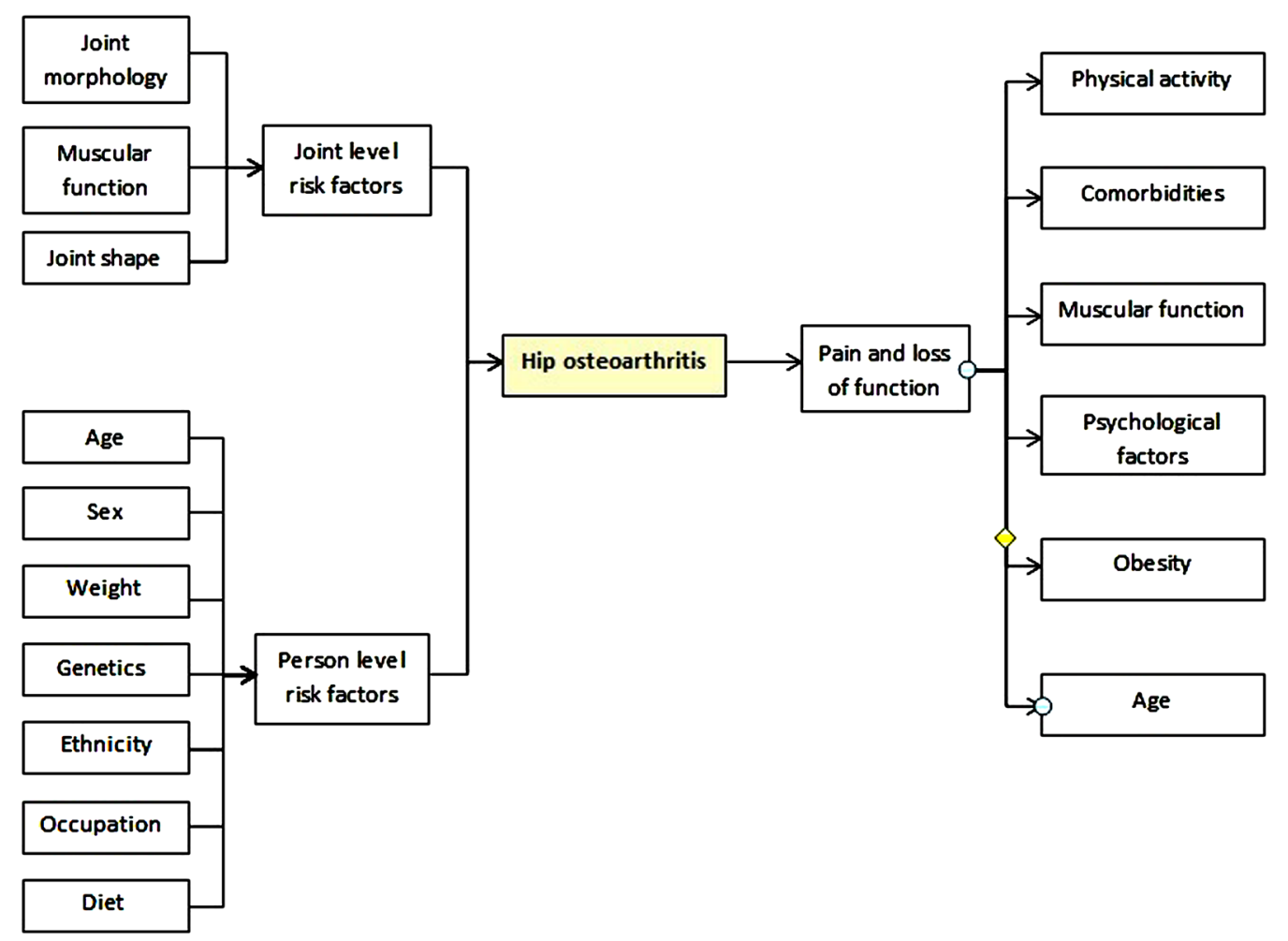

Fig. 1 Risk factors for hip osteoarthritis

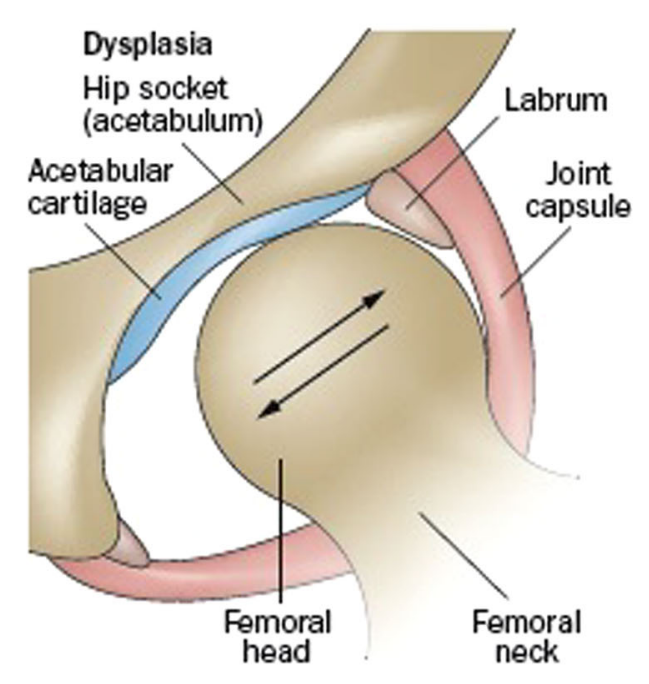

Fig. 2 Developmental dysplasia of the hip (DDH). The femoral head is less stable within the shallow acetabulum (image on left), causing the distribution of shear forces that

tends to occur earlier in life [33], but in milder dysplasia can occur much later [41]. Surgical strategies to restore normal joint loading damage the articular cartilage and predispose to labral tears (image on right) [31] (reprinted by permission from Macmillan Publishers Ltd)

patterns have been developed, involving pelvic osteotomy to reorient the acetabulum to reduce pathological force distribution patterns, thus 
preventing or at least substantially delaying the onset of hip OA [42].

\section{Femoroacetabular Impingement (FAI)}

FAI is likely a more prevalent underlying cause for the development of hip OA. Ganz and colleagues described two different morphological patterns of FAI: cam and pincer FAI [38]. In cam FAI, the predominant morphological abnormality is a thickened, aspherical femoral head-neck junction (Fig. 3). When the hip joint is flexed, the cam lesion on the proximal femur abuts against the anterosuperior labrum of the hip, compressing it and pushing it outwards. Meanwhile the acetabular cartilage is compressed and pushed inwards by the shearing force exerted by the cam lesion. The overall effect is separation of the acetabular cartilage from the labrum and delamination of acetabular cartilage from the subchondral bone [43]. In pincer FAI, there is a deepened acetabulum, with acetabular over coverage of the femoral head. As a result the femoral neck abuts against the acetabular labrum, exerting compressive forces that result first in damage of the labrum and eventually the underlying cartilage (Fig. 4) in a thin circumferential band around the acetabular rim [38, 43, 44]. Because the most common movement of the hip joint is flexion, a preponderance of the labral lesions are still found anterosuperiorly with pincer FAI, as with cam FAI. However with pincer FAI, lesions are also commonly found posteroinferiorly on the acetabular rim [43]. These lesions are believed to occur as a result of continued flexion of the hip joint after the femoral neck is already abutting against the anterosuperior acetabular rim, causing the femoral head to sublux posteriorly, thus producing a so-called contre-coup lesion in the femoral head and posterioinferior acetabulum [37, 43]. Although two distinct pathomechanisms for FAI exist, the reality is that in most cases a combination of both types of impingement are present [45].

Estimates for the prevalence of FAI morphology in the general population have varied wildly owing to significant heterogeneity in the definition of FAI morphology used and in the populations sampled $[47,48]$. The estimated prevalence of cam morphology has varied between $10 \%$ and $25 \%$ of the population $[49,50]$. A systematic review found that radiographic evidence of pincer-type morphology is present in almost two-thirds of the population [48], although this figure is likely inflated because of the poor reliability and specificity of many of the radiographic signs considered suggestive of pincer morphology [51]. Other disorders arising as
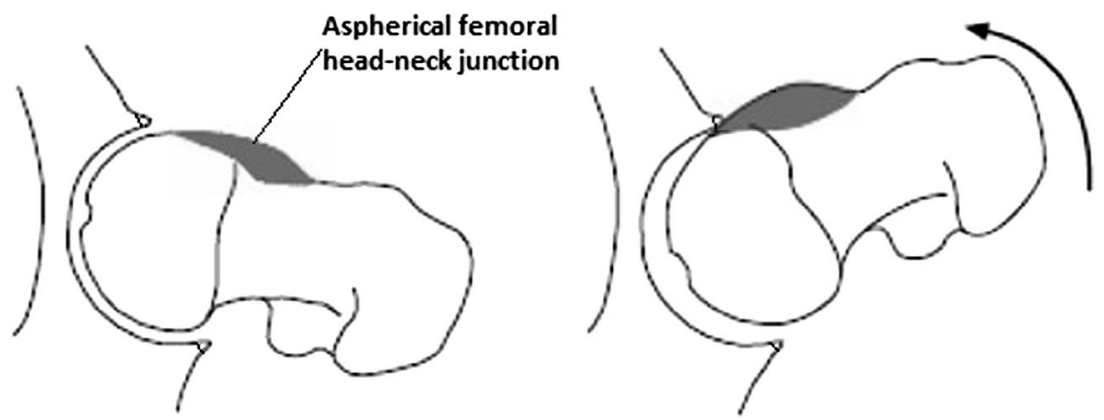

Fig. 3 Cam impingement. The cam lesion abuts against the labrum, pushing it outwards and compressing the acetabular cartilage inwards. The labrum separates from

the cartilage and the acetabular cartilage delaminates from the bone [46] (reproduced with permission from Springer) 


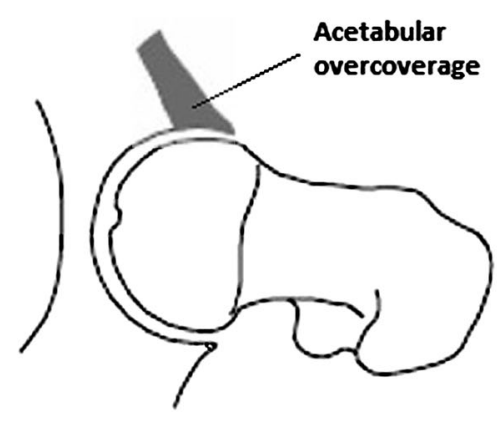

Fig. 4 Pincer impingement. Owing to acetabular over-coverage, the femoral neck abuts against the hip labrum, damaging the labrum and eventually the underlying cartilage. A contre-coup lesion can also occur, where continued flexion of the hip, after the femoral neck

developmental abnormalities of the hip, including slipped capital femoral epiphysis and Legg-Calvé-Perthes disease are also associated with FAI morphology, although these make up only a small minority of hips with FAI [52]. The proportion of the population with symptomatic FAI is only a fraction of those with FAI morphology, and an important but not yet well-understood area of research lies in determining the cause of onset of symptoms in some with FAI morphology but not others. It is widely recognized that symptomatic FAI occurs most commonly in young, active people, with particularly increased prevalence rates in athletes [53]. Symptoms most commonly include insidious onset of groin or buttock pain exacerbated by physical activity, oftentimes combined with loss of terminal hip range of motion [54]. Although osseous abnormalities underlie FAI morphology, symptomatic FAI is postulated to arise as a result of labral and/or chondral injury occurring secondarily to bony impingement [53].

The poor predictive value of FAI morphology for symptomatic disease $[55,56]$ is likely in part related to the inadequacy of the imaging

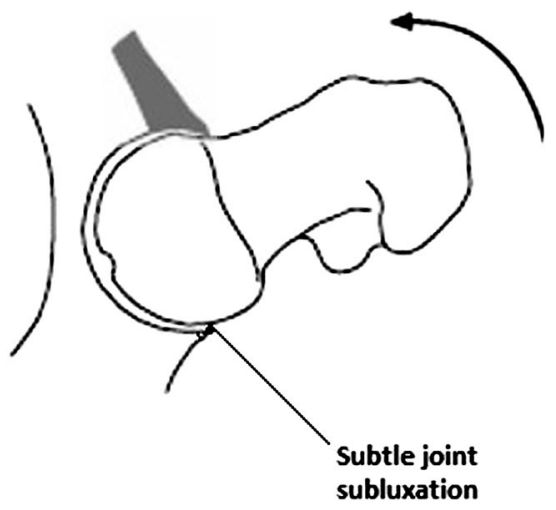

is already abutting against the acetabular rim, causes subtle joint subluxation and damage to the acetabular cartilage. The labrum separates from the cartilage and the acetabular cartilage delaminates from the bone [46] (reproduced with permission from Springer)

parameters used to diagnose FAI morphology. Each FAI parameter is measured on a two-dimensional planar image, and is usually considered in isolation from other FAI-relevant parameters, an approach that fails to accurately reflect the dynamic interaction between the proximal femur and acetabulum. For instance, a femoral head classified as having cam morphology on account of an alpha angle greater than $55^{\circ}$ (Fig. 5a) in reality may not suffer any functional impingement due to the relatively shallow acetabulum with which it is interacting [57]. Likewise, an acetabulum considered to exhibit pincer morphology on account of an increased lateral center edge angle (Fig. 5b) may not experience true impingement if it occurs in conjunction with a spherical femoral head and a suitably anteverted acetabulum. True FAI is a dynamic, three-dimensional condition affected by the complex relationship between various anatomical parameters. Anatomical parameters implicated in FAI morphology have included the alpha and lateral center edge angles [58], the extent of acetabular retroversion [59] and femoral anteversion [60], and the femoral neck 


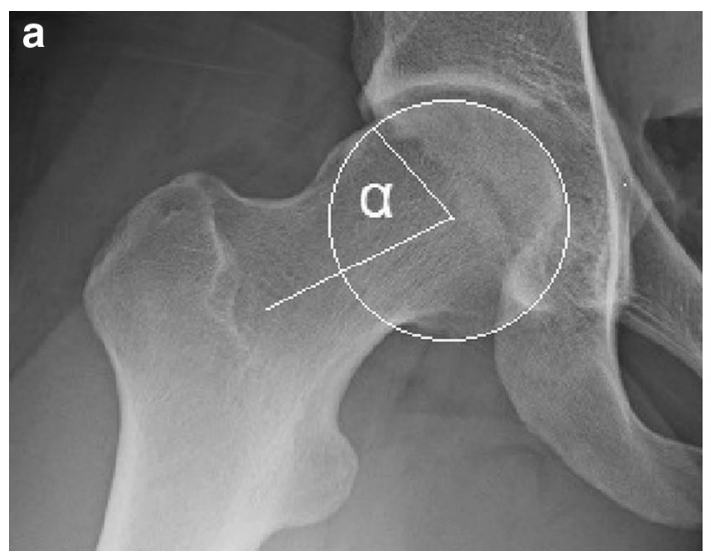

Fig. 5 Diagnosis of FAI morphology. The a alpha angle and $\mathbf{b}$ lateral center edge angle are two of the imaging parameters commonly used to classify FAI morphology. The alpha angle (a), shown here on a modified Dunn $\mathrm{X}$-ray view, is the angle formed by the femoral neck axis and a line connecting the center of the femoral head to the point at which the head-neck contour becomes aspherical.

shaft angle [61]. Bouma and colleagues have attempted to develop a model that uses CT and motion simulation software to integrate these parameters, with the aim of producing a single, comprehensive measure of FAI morphology [62]. This approach is still in its infancy and requires further study to refine developed models and establish their clinical relevance. However the notion of a more comprehensive and functionally accurate measure of FAI morphology holds promise for improving the accuracy of FAI diagnosis and prediction of hip OA risk for screening purposes.

There is growing evidence that FAI is an important cause of hip OA. Numerous studies have demonstrated an association between the presence of FAI morphology and cartilage damage [38, 43, 44, 63, 64, 65, 66, 67, 68]. For example, a study in which 244 asymptomatic young males underwent MRI found that the 67 participants with cam lesions had increased occurrence of labral lesions, impingement pits, and labral deformities [64]. Zeng and colleagues investigated the association between hip

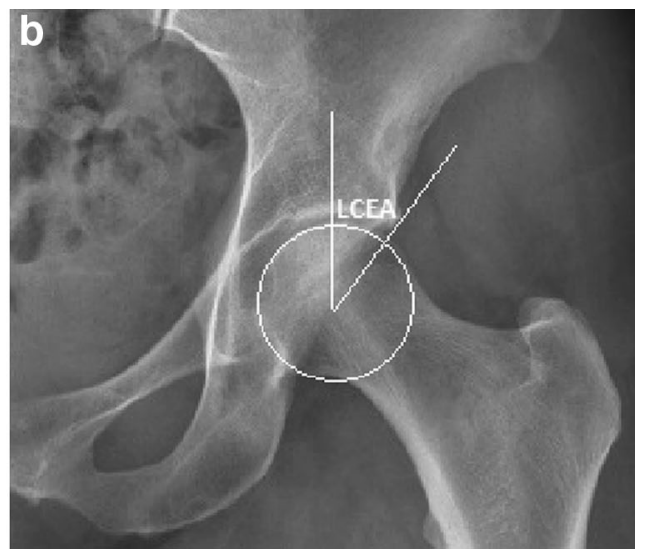

Greater than $50^{\circ}$ or $55^{\circ}$ is often considered suggestive of cam morphology. The lateral center edge angle (b), measured on an AP pelvic X-ray, is the angle formed by a vertical line connecting the center of the femoral head with the lateral edge of the acetabulum. Greater than $40^{\circ}$ is often considered suggestive of pincer morphology

morphology and hip OA by comparing the 3D CT reconstruction of 186 normal hips to those of 132 hips with mild-moderate hip OA. Participants with OA demonstrated more features consistent with impingement morphology: less spherical femoral heads, less concavity of the femoral head-neck junction, less acetabular and femoral neck anteversion, and greater acetabular coverage [68]. Studies using delayed gadolinium-enhanced MRI of cartilage (dGEMRIC), a technique used to quantify the glycosaminoglycan (GAG) content of cartilage and thus detect GAG loss that is associated with the early onset of OA $[69,70]$, have demonstrated that people with FAI are more likely to have damaged cartilage suggestive of early OA [44, 71], and the extent of this damage correlates with severity of cam deformity [72]. In recent years active shape modelling of hips has been shown to predict future risk of hip OA, with various FAI-type morphologies being shown to correlate with increased hip OA incidence [73, 74]. However the fact that severe morphological 
abnormalities do not always bring about hip OA $[33,75,76]$ suggests that there are more variables at play in the etiology of hip OA than joint morphology alone.

\section{Periarticular Musculature of the Hip Joint}

The importance of the periarticular musculature for shock absorption has been recognized as a characteristic common to many joints [9]. The deep stabilizing muscles of the hip likely play a role in absorbing shock and protecting the joint from aberrant movement patterns, although there is a paucity of research in this area. Physiotherapy-led rehabilitation for FAI has the strengthening and conditioning of the periarticular hip musculature as its cornerstone. Specifically, it aims to improve control of the femoral head by strengthening the deep stabilizing hip muscles, particularly the deep hip abductors and external rotators, so as to reduce impingement that occurs when the hip moves into the commonly exacerbating position of combined flexion, internal rotation, and adduction [77-79]. A recent review on the limited body of research on physiotherapy-led management of FAI suggested that it confers symptomatic benefit, although further study is needed comparing its efficacy to other treatment modalities such as hip arthroscopy [80]. It seems highly plausible that muscular dysfunction of the deep hip stabilizers plays a role in pathological hip joint biomechanics. In knee OA, an analogous relationship with quadriceps strength is well recognized [81-83].

The possible role of muscular dysfunction in biomechanical insult at the hip joint is yet to be rigorously studied. Three studies examining hip muscle weakness in symptomatic FAI found hip abductor weakness [84-86]; two also reported hip flexion weakness $[84,86]$, and weakness in other directions of movement was identified in isolated studies. Biomechanical gait analysis found abnormally high levels of muscular co-contraction in FAI-affected hips compared to matched controls [87]. A systematic review of muscle weakness in hip OA [88] found eight cross-sectional studies examining muscle strength, all of which reported an association of hip and lower limb weakness with hip OA. Weakness was commonly found in hip and knee flexion and extension, as well as in hip abduction and adduction. Muscle weakness associated with FAI and hip OA could be due to a variety of different factors, including pain inhibition, muscle disuse atrophy, or aberrant joint mechanics. The role of the deep hip stabilizers in aberrant joint mechanics, possibly leading to the onset of FAI and subsequent hip OA, warrants further study. Moreover, targeted research into the specific muscular changes associated with successful physiotherapy treatment for FAI is required to better understand the role the periarticular muscles play in the etiology of hip OA.

\section{Joint Injury and Labral Tears}

A well-established risk factor for $\mathrm{OA}$ is joint injury, the archetypal example being anterior cruciate ligament rupture of the knee, which substantially increases risk of knee osteoarthritis in the years following injury [89]. In the hip, a common form of joint injury is an acetabular labral tear, which warrants further study as a possible contributing factor to the development of hip OA. Acetabular labral tears are very common, estimated to be present in $66 \%$ of people with mechanical hip pain [90] and roughly $39 \%$ of the asymptomatic population [91], with increasing age an important risk factor. The etiology of such tears can be an acute traumatic event, degenerative change of insidious onset such as is often caused by chronic impingement, idiopathic or occasionally congenital [92]. There is a strong 
association between abnormal osseous morphology and the presence of symptomatic labral tears [38, 43, 44]. However case series have found that $13 \%$ to $30 \%$ of patients undergoing surgery for repair of symptomatic labral tears had no sign of abnormal osseous morphology [93, 94], suggesting that FAI and dysplasia are not the only cause of symptomatic acetabular labral tears. Acute traumatic events have been identified as the cause of symptomatic labral tears in approximately $20 \%$ of cases [92-94], oftentimes accompanying sudden twisting motions [95]; however, it is likely that occult traumatic events lead to more cases. The acetabular labrum has important and under-recognized anatomical functions in the hip [96]. Cadaveric studies have found that the labrum increases the articular surface area of the acetabulum by $22 \%$ and contributes up to $33 \%$ of the hip joint's volume [97, 98]. An intact labrum is believed to provide a suction seal that contributes to the stability of the hip joint, as well as distributing pressure more evenly between the femur and acetabulum, while maintaining synovial fluid important for lubrication within the joint space [99, 100]. Conversely, tears are believed to reduce the capacity of the labrum to perform these important functions, resulting in reduced hip joint stability and suboptimal femoroacetabular pressure distribution [100].

The extent of labral damage has been shown intraoperatively and on magnetic resonance arthrography (MRA) to correlate both with the amount of chondral damage and the extent of bone marrow lesions in people with symptomatic labral tears [90, 101, 102]. Since chondral damage and bone marrow lesions are two characteristic features of hip OA, it may be inferred that labral tears are intimately related to the OA process in the hip. It is likely that labral and chondral damage often occur simultaneously as a result of the same traumatic event or because of exposure to the same bony impingement pattern over time. There is also the possibility that in some cases the occurrence of a labral tear itself, for instance via trauma to the hip joint, could be the initial event that alters the biomechanical environment of the joint and contributes to the onset of joint damage that leads to hip OA $[90,101]$. Isolated labral tears are much more prevalent in younger people, while labral tears accompanying chondral damage tend to occur later in life, lending support to the notion that labral tears may precede chondral damage in many cases, possibility contributing to its onset [102]. In many cases both of these scenarios may even occur, with bony impingement causing labral damage; the labral damage itself subsequently worsens the hip's biomechanical function, with a positive feedback cycle thus being created that leads to accelerated development of hip OA. The pathophysiology of labral tears and their relationship with hip $\mathrm{OA}$ is incompletely understood and warrants further study.

\section{Whole Person Level Risk Factors}

Whole person level risk factors can be understood as influencing risk of hip OA development through the effect they exert on joint level risk factors.

Age

The very strong relationship between $\mathrm{OA}$ and age is well-recognized in all joints [103], including the hip. In the Johnston County Project only $5.9 \%$ of people in the $45-54$ age group suffered from symptomatic hip OA; 
however, in people over 75 this figure increased to $17 \%$ [18]. Age-related biological changes such as cellular senescence have been observed in articular cartilage, with chondrocytes undergoing changes such as telomere shortening [104]. Declining chondrocyte density has also been demonstrated [105], resulting in decreased extracellular matrix synthesis and production of smaller, more irregular proteoglycans [106]. Similar change occurs in other joint tissues such as bone and ligaments as part of the ageing process. The gradual onset of sarcopenia and frailty with ageing have a complex flow on effects that can place biomechanical stress on the hip joint and may predispose to joint damage [107]. In the context of a joint under mild biomechanical stress due to subtle morphological abnormalities or poor periarticular muscular support, these age-related changes are more likely to disrupt the equilibrium between joint tissue synthesis and degradation.

\section{Sex}

Overall the relationship between sex and hip $\mathrm{OA}$ is unclear; if a relationship does exist it seems it is weaker at the hip compared to other joints, where female sex is often considered a risk factor. A large meta-analysis considering more than 14,000 people suggested there was no difference in hip OA prevalence or severity between men and women [108]. Counter-intuitively, the same meta-analysis found an increased incidence of hip $\mathrm{OA}$ in females, although there were only two such studies used for pooling in this meta-analysis because studies looking at OA incidence are less common. The Framingham Osteoarthritis Study found a higher prevalence of radiographic hip OA in men compared to women, but no significant difference in symptomatic hip OA risk [16].

\section{Weight}

The best available evidence suggests that increased BMI is associated with increased risk of hip OA, although this relationship is less marked than the strong correlation between BMI and knee OA [109, 110]. A large meta-analysis [109] found that a dose-response relationship exists between BMI and risk of hip OA, with each five-unit increase in BMI associated with an $11 \%$ increased risk of hip OA. The association was consistent across both sexes, cohort and cross-sectional studies, and across all definitions of OA used. In previous studies, the evidence found linking hip OA and weight has been inconsistent [111], possibly because of population differences combined with the relative weakness of the effect of obesity on hip OA risk compared to knee OA.

Two mechanisms are proposed to link hip OA and increased BMI. Firstly, increased body weight increases biomechanical loading at the hip joint and thus leads to larger joint stresses, particularly in the presence of any joint level risk factors [109, 112]. Secondly, a metabolic theory has been proposed, whereby systemic pro-inflammatory factors associated with obesity act on joints to increase risk of $\mathrm{OA}$ [113]. This is supported by the association between obesity and hand OA [114], despite the hand not being a weight-bearing joint.

\section{Genetics}

Genetic factors are very important in hip OA; twin studies have suggested that genetic factors contribute approximately $60 \%$ of hip OA risk [115]. Familial clustering of hip OA has been observed, with increased relative risk of total hip arthroplasty (THA) demonstrated for first-, second-, and third-degree relatives of people who had undergone THA [116]. Genome-wide association studies have identified several candidate genes for hip OA, although many of 
these have not been found to be reproducible across studies [117]. Tellingly, the majority of genes identified as most likely to increase risk of hip OA thus far are genes associated with synovial joint development, which supports the notion of congenital/developmental hip joint deformity being paramount in hip OA development [31]. Sandell proposed a model (Fig. 6) that ties the continuous spectrum of morphological abnormalities in the hip joint to genes implicated in the development of hip OA [31]. In future studies further elucidation of the exact genes and mutations involved in hip OA is necessary to enable the possibility of screening and calculation of hip OA risk prior to disease onset.

\section{Ethnicity}

Great variation in the prevalence of hip OA has been noted between races. Most notably, the Beijing Osteoarthritis Study found hip OA to be $80 \%$ to $90 \%$ less prevalent in the Chinese population compared to Caucasian populations in the USA [14], a finding replicated in other studies [118, 119]. This may be explained by differences in hip morphology between the two races, with substantially higher rates of femoral head asphericity and pincer impingement morphometry having been found in white women compared to Chinese women [120]. Another likely contributing factor is genetic differences between the races, many of which are probably expressed in hip morphology.

\section{Occupation}

It has been suggested that increased levels of high-impact physical activity, via occupational exposure or long-term participation in high-impact sports, may predispose to the development of hip OA. The underlying mechanism may be similar to that of obesity, with high-impact joint loading causing biomechanical stress to the joint, especially in a hip that is already predisposed via morphological abnormality or suboptimal periarticular muscular support. Epidemiological evidence has suggested that occupations involving heavy manual work have increased risk of developing hip OA [121, 122]. In particular, farmers are at increased risk, with those who have farmed for more than 10 years at more than three times relative risk compared to the general population [121]. The exact patterns of movement or activities responsible for the increased risk are unknown, although heavy lifting may play a significant role.

It has been proposed that athletes participating in high-impact sports are

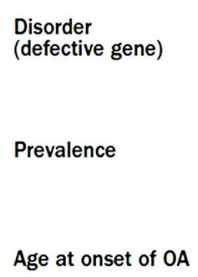

Fig. 6 The genes responsible for the development of OA have been proposed to exist on a continuum related to joint morphology. Some defective genes are expressed in markedly abnormal joint morphology, such as in some chondrodysplasias, causing early-onset OA. Other more

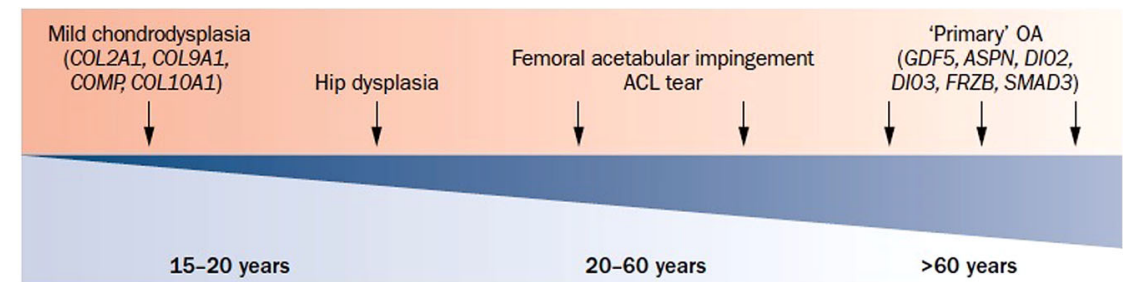

common genetic defects are expressed in subtle morphological aberrations that cause late-onset OA, previously considered primary OA [31] (reprinted with permission from Macmillan Publishers Ltd) 
predisposed to developing hip OA. This is difficult to assess because of the confounding factor of higher rates of traumatic joint injury in athletes owing to their sports participation, as well as great heterogeneity between studies related to this topic $[123,124]$. Two mechanisms may predispose athletes to increased risk: firstly, increased high-impact joint loading as described for heavy manual workers; secondly, increased prevalence of cam morphology which may be caused by high levels of physical activity during a critical period during adolescence while osseous development is still occurring [125]. Several studies have found increased prevalence of FAI morphology amongst professional athletes in high-impact sports such as basketball, ice hockey, and football [126-128], as well as increased prevalence of symptomatic FAI [54]. Although long-term participation in high-impact sport or heavy-duty manual labor may predispose to hip OA, it is important to note that there is no solid epidemiological evidence to support the misperception that exercise or physical activity has a deleterious effect on risk of hip OA in the general population.

\section{Diet}

It has been suggested that dietary factors may be important in affecting OA risk [129], although strong evidence to support this is lacking. Several vitamins and minerals have been suggested as potentially important, some of the most commonly implicated being vitamins $\mathrm{D}, \mathrm{K}$, and C. Vitamin D was thought to be relevant to OA risk on account of its role in bone mineralization. A recent meta-analysis found no association between serum vitamin $\mathrm{D}$ levels and prevalence or incidence of hip, knee, or hand OA [130], despite early studies on vitamin $\mathrm{D}$ and $\mathrm{OA}$ suggesting a possible relationship [131, 132]. Low vitamin $\mathrm{K}$ has been associated with knee and hand $\mathrm{OA}$ in a small number of studies [133-135]; however, supplementation with vitamin $\mathrm{K}$ has not demonstrated any effect on disease progression [136]. Vitamin C and various other antioxidants have also been investigated for a possible association with $\mathrm{OA}$ but results have been inconclusive [137-139]. At present there is a lack of high-quality evidence relating hip OA to dietary factors.

\section{MANAGEMENT}

Unfortunately the management of hip OA remains reactionary and palliative. Management begins after the onset of symptoms, by which point the disease is usually well established and significant joint damage has already been incurred. The focus is on symptom management, which is usually only moderately effective. Disease-modifying interventions, although the subject of a great deal of research, have thus far remained elusive in hip OA. Eventually joint amputation occurs in the form of a total hip replacement (THR), which although highly effective in relieving symptoms, occurs at substantial cost and with risk of morbidity. A shift to focus the efforts of research and public health intervention on primary prevention may hold the key to enhancing the current model for the management of hip OA.

\section{Primary Prevention}

Modifiable risk factors represent the lowest hanging fruit in terms of OA prevention. A problem with hip OA is that of the known risk factors, few are easily modifiable. Body weight is modifiable, and hence weight loss in overweight or obese patients should be 
actively pursued to reduce the risk of disease development and possibly delay disease progression [5-7]. Patient education around this issue is vital in the primary healthcare setting. The role that periarticular muscular factors play in the etiopathogenesis of hip OA requires investigation. If well-designed studies determine that the periarticular musculature plays a sufficiently important role in hip joint biomechanics to influence hip OA risk, this may become a fertile field for physiotherapy-led primary preventative measures.

In the last 15 years it has emerged that possibly the most important risk factor for hip OA development is abnormal hip joint morphology, particularly in the form of FAI. There is a large body of research activity being conducted to identify the environmental exposure/s that may trigger the development of this shape abnormality. If this is found it may enable restriction of this environmental exposure through public health interventions. Until the day when genetic editing is available and the genes involved in hip OA are fully understood, the only mechanism available for alteration of joint morphology is surgical intervention. Hip arthroscopy to alter joint shape is an increasingly utilized procedure in the treatment of symptomatic FAI [140]; however, clinical trials are still needed that compare outcomes between hip arthroscopy and conservative management to establish the procedure's efficacy [141]. In particular, longitudinal clinical trials are needed to determine the efficacy of surgical and physiotherapy-based interventions for modification of future hip OA risk. It is important to note that joint-preserving surgery should be pursued before the onset of hip OA or early in the disease course, as emerging evidence suggests these patients obtain much greater benefit from the procedure than those with advanced hip OA, for which THA is more appropriate $[142,143]$. The question of whether asymptomatic FAI of sufficient morphological severity warrants surgical intervention to reduce future hip OA risk also requires investigation.

\section{Current Management Approaches}

\section{Conservative Non-Pharmacological Management}

Rehabilitation for hip OA encompasses several different aspects, including patient education, weight management, land- and water-based exercise, and strength training [144]. While consistent evidence supports the efficacy of these strategies in the management of knee OA [145], the evidence in hip OA is far more variable [144]. Weight loss is recommended for people with hip OA who are overweight/obese; however unlike knee OA, there is a paucity of clinical trial evidence for weight loss in hip OA [146]. A cohort study reported that a combined dietary and exercise weight loss program improved functional symptoms and reduced pain [147]; however, much further study is needed to establish the efficacy of weight loss in hip OA conclusively.

Exercise therapy is widely recommended in clinical guidelines for hip OA management [5-7]. Overall there is evidence that exercise offers small to moderate benefit in reducing pain and improving function in hip $\mathrm{OA}$ $[146,148,149]$, although the strength of this evidence is less than for knee OA [150]. Small clinical trials have recently suggested exercise therapy may postpone the need for THA [151] and may reduce medical expenditure for people with hip OA [152]. There are various activities included under the banner of exercise therapy, including strengthening, aerobic, and flexibility activities, many of which can be carried out on land or in the water. No particular activity type 
has been shown to produce superior results, and thus it is recommended that exercise programs be personalized to reflect the unique needs of each patient [153].

Physiotherapy for hip OA usually includes physiotherapist-led exercise therapies in conjunction with manual therapy. The value of physiotherapy in the management of hip OA is a hotly contested issue, with recent evidence suggesting it offers little benefit beyond what could be expected from a self-guided exercise program [149]. Systematic reviews on the topic have reported no benefit from the use of manual therapy in treating hip OA, nor any additional benefit when manual therapy is combined with an exercise program than is obtained from exercise alone [154, 155]. A recent clinical trial comparing physiotherapy-led management to sham therapy found no benefit of physiotherapy on pain or function [156]. More high-quality research is needed in this area, but the limited evidence currently available does not establish physiotherapy as effective in treating hip OA. A novel strategy being investigated for a potential role in modifying biomechanics to treat hip OA is bracing, although this research is still very much in its infancy [157-160].

\section{Pharmacological Management}

A myriad of different pharmacological compounds have been produced with the aim of treating OA, although few trials have focused on hip OA specifically. Pharmacological treatments include those administered topically, orally, and by intra-articular injection. Some treatments aim to relieve symptoms alone, whereas others, disease-modifying osteoarthritis drugs (DMOADs), attempt to alter the course of disease. DMOADs generally have shown promise in preclinical trials but results have proved disappointing in later phase trials, with disease-modifying efficacy of any agent yet to be convincingly established [161-163]. Historically DMOADs have aimed to inhibit steps in the pathway of cartilage degradation or stimulate steps in cartilage synthesis [164]. However as the understanding of the pathogenesis of $\mathrm{OA}$ has progressed to become less cartilage-centric, DMOADs targeting other joint tissues such as synovium and bone have been developed [162]. DMOADs have included, among others, glucosamine sulfate, chondroitin sulfate, doxycycline, bisphosphonates, diacerein, matrix metalloprotease inhibitors (MMPs), avocado soy bean unsaponifiables, platelet-rich plasma (PRP) injections, strontium ranelate, and sprifermin [163, 164].

Until recently, clinical guidelines have recommended that symptom management in OA begin with paracetamol [5, 7]. However current large-scale meta-analyses have found strong evidence that paracetamol confers a clinically unimportant reduction in short-term pain for hip and knee OA $[165,166]$. In the near future clinical guidelines will likely be adapted to reflect the lack of efficacy of paracetamol for hip and knee OA. NSAIDs have a well-recognized role in the symptomatic relief of OA and can be administered topically or orally. A recent meta-analysis reported strong evidence that diclofenac and etoricoxib are the most efficacious NSAIDs for pain relief in hip and knee OA, producing a moderate to large effect size [166]. However because of the risk of gastrointestinal and cardiovascular adverse events associated with their use, clinical guidelines recommend the use of NSAIDs for hip OA be restricted to the lowest possible doses and duration $[5,7]$. Topical NSAIDs provide local pain relief in hand and knee OA; however, the depth of the hip joint renders it an inappropriate target for topical NSAIDs [167] 
and hence there are no recommendations for their use in hip OA $[5,7]$.

Duloxetine is a selective serotonin and norepinephrine reuptake inhibitor (SNRI) posited to inhibit pain via mechanisms acting on the central nervous system. Although untested in hip OA, phase III clinical trials have reported reduced pain and improved function associated with duloxetine use in knee OA [168, 169]. Further study of the efficacy of duloxetine for symptomatic management of hip OA is warranted, especially given its favorable safety profile [170]. Where other management strategies are unable to relieve symptoms sufficiently, tramadol, a weak non-narcotic opioid, may be considered for pain relief, although a drawback is its side-effect profile [171]. Non-tramadol opioids are not routinely recommended in hip $\mathrm{OA}$, as in most cases the burden of side effects and possible adverse events outweighs reductions in pain [172].

Intra-articular injection therapies for hip OA are an area of increasing interest. The available evidence suggests that intra-articular corticosteroid injections (IASI) offer symptomatic relief in hip OA. A recent meta-analysis identified five clinical trials, each with fewer than 100 participants, examining the efficacy of IASI specifically in hip OA [173]. With regards to pain reduction, it reported a large effect size 1 week post-injection and a moderate effect size after 8 weeks, although treatment effect declined thereafter. Guidelines currently recommend the use of IASI as an adjunct to other treatments for pain relief in hip OA $[5,7]$.

Hyaluronic acid (HA), a glycosaminoglycan normally constituent in synovial fluid but present in decreased concentrations in $\mathrm{OA}$, is a compound used in clinical practice for its possible anti-inflammatory and analgesic properties. The evidence for the efficacy of HA is conflicting [174-177]. A challenge in interpreting findings is the great heterogeneity between studies with regard to the amount and type of HA injected, the number of doses given, and the length of follow-up [178]. Clinical guidelines do not currently recommend HA injections for hip or knee OA $[5,7]$.

There have been relatively few studies investigating the use of platelet-rich plasma (PRP) as an intra-articular injection therapy in hip OA [179], and hence it is too early to comment on its efficacy [180]. Two small clinical trials have investigated PRP injections for hip $\mathrm{OA}$, in both cases comparing to HA; one reported no difference between the two treatments [181], while the other found PRP to be more efficacious at 2- and 6-month follow-up [182]. For each of these injection therapies there is a great need for more high-quality clinical trials to inform clinical practice.

\section{Surgical Management}

More than 1 million people worldwide undergo THA annually, over $90 \%$ of these because of end-stage hip OA [183]. Although THA occurs at substantial expense to individuals and the healthcare economy, several cost-benefit analyses have demonstrated that THA is a highly cost-effective procedure for people with hip OA not responding to conservative management approaches [184]. At 10 years post-THA more than $95 \%$ of implanted hips are still functioning, and this figure remains above $80 \%$ after 25 years [183, 185]. Following a course of failed conservative therapy, research suggests that patient outcomes are enhanced when THA is undergone quickly rather than waiting until the condition deteriorates further, since poor function preoperatively is correlated with worse postoperative function [183, 186]. 
Although THA is an effective management approach for patients with hip OA who have exhausted other options, the need for this operation in the future will hopefully be reduced by an early intervention, disease-modifying approach to hip OA management.

Hip resurfacing was developed as an alternative to THA for younger, more active patients in the interests of bone preservation to enable easier revision surgery and reduce the chance of dislocation. A systematic review identified substantially higher rates of revision and reoperation for hip resurfacing compared to THA [187]. Current evidence suggests hip resurfacing is a suitable option only for carefully selected patients; usually young, active male patients with primary OA and a sufficiently large femoral head size [188, 189].

\section{Implications for Future Management}

The symptomatic management of hip OA remains an important area of research to enhance quality of life for those suffering from the disease. However disease-modifying treatment represents the holy grail of OA research. Although treatment modalities such as DMOADs aim at disease modification, a problem with their approach is that they are not based on the condition's joint-specific etiopathogenesis. We know that $\mathrm{OA}$ is not a single disease affecting several joints in the body, but rather is a distinct condition at each joint, with unique etiological factors and responses to treatments. With this in mind, it seems improbable that a single pharmacological compound acting on all joints will be a curative solution. In hip OA it is becoming increasingly evident that biomechanical factors are the primary driver of the condition's etiopathogenesis, and thus treatments addressing these factors may offer better chances of effecting a cure [9].

Of the currently employed treatment strategies, physiotherapy seems the modality most congruous with the goal of joint-specific, biomechanically oriented management, yet paradoxically it has not proven to be among the more efficacious treatments. However physiotherapy, and indeed any treatment aiming at disease modification, faces an uphill battle in treating already well-established hip OA. By the time treatment is begun, substantial joint injury has already been incurred, likely worsening the maladaptive biomechanical environment that led to the development of $\mathrm{OA}$ in the first place. Expecting any treatment modality to overcome an already substantially damaged joint is probably unrealistic.

\section{CONCLUSION}

Our hypothesis is that true inroads in reducing the burden of hip OA are most likely to be seen with an increased focus on risk factor modification prior to or in the early stages of the condition's pathogenesis. It is important that the risk factors identified in this review are considered during the development of new therapeutic approaches and public health interventions for hip OA. Risk calculators such as those that currently exist for heart disease could be developed, incorporating imaging and even genetic biomarkers to enable stratification of people into varying risk levels for appropriate monitoring and management. With improved understanding of the etiopathogenesis of hip OA, intervention prior to or early in the disease course in a 
disease-modifying manner is likely to become feasible in the future. The management of hip OA has the potential to be an area of medicine undergoing substantial advancement in the decades to come.

\section{ACKNOWLEDGMENTS}

No funding was received for publication of this article. Professor Hunter receives a National Health and Medical Research Council (NHMRC) Practitioner Fellowship. All named authors meet the International Committee of Medical Journal Editors (ICMJE) criteria for authorship for this manuscript, take responsibility for the integrity of the work as a whole, and have given final approval to the version to be published.

Disclosures. Nicholas Murphy and Jillian Eyles declare that they have no conflict of interest. Professor Hunter is an Associate Editor for Arthritis and Rheumatology and consultant to Flexion, Nestle, and Merck Serono.

Compliance with Ethics Guidelines. This article is based on previously conducted studies and does not involve any new studies of human or animal subjects performed by any of the authors.

Open Access. This article is distributed under the terms of the Creative Commons Attribution-NonCommercial 4.0 International License (http://creativecommons.org/licenses/ by-nc/4.0/), which permits any noncommercial use, distribution, and reproduction in any medium, provided you give appropriate credit to the original author(s) and the source, provide a link to the Creative Commons license, and indicate if changes were made.

\section{REFERENCES}

1. Murphy LB, Helmick CG, Schwartz TA, et al. One in four people may develop symptomatic hip osteoarthritis in his or her lifetime. Osteoarthr Cartil. 2010;18(11):1372-9.

2. Culliford DJ, Maskell J, Kiran A, et al. The lifetime risk of total hip and knee arthroplasty: results from the UK general practice research database. Osteoarthr Cartil. 2012;20(6):519-24.

3. Neogi T, Zhang Y. Epidemiology of osteoarthritis. Rheum Dis Clin N Am. 2013;39(1):1-19.

4. Gold GE, Cicuttini F, Crema MD, et al. OARSI clinical trials recommendations: hip imaging in clinical trials in osteoarthritis. Osteoarthr Cartil. 2015;23(5):716-31.

5. Hochberg MC, Altman RD, April KT, et al. American College of Rheumatology 2012 recommendations for the use of nonpharmacologic and pharmacologic therapies in osteoarthritis of the hand, hip, and knee. Arthritis Care Res. 2012;64(4):465-74.

6. Fernandes L, Hagen KB, Bijlsma JW, et al. EULAR recommendations for the non-pharmacological core management of hip and knee osteoarthritis. Ann Rheum Dis. 2013;72(7):1125-35.

7. National Clinical Guideline Centre. National Institute for Health and Clinical Excellence: guidance. Osteoarthritis: care and management in adults. London: NICE/National Clinical Guideline Centre; 2014.

8. Lane NE, Brandt $\mathrm{K}$, Hawker G, et al. OARSI-FDA initiative: defining the disease state of osteoarthritis. Osteoarthr Cartil. 2011;19(5):478-82.

9. Brandt KD, Dieppe P, Radin EL. Etiopathogenesis of osteoarthritis. Rheum Dis Clin N Am. 2008;34(3):531-59.

10. Arden N, Nevitt MC. Osteoarthritis: epidemiology. Best Pract Res Clin Rheumatol. 2006;20(1):3-25.

11. Altman R, Alarcon G, Appelrouth D, et al. The American College of Rheumatology criteria for the classification and reporting of osteoarthritis of the hip. Arthritis Rheum. 1991;34(5):505-14.

12. Kellgren JH. Atlas of standard radiographs: the epidemiology of chronic rheumatism. Oxford: Oxford University Press; 1963.

13. Pereira D, Peleteiro B, Araujo J, Branco J, Santos RA, Ramos E. The effect of osteoarthritis definition on 
prevalence and incidence estimates: a systematic review. Osteoarthr Cartil. 2011;19(11):1270-85.

14. Nevitt MC, Xu L, Zhang Y, et al. Very low prevalence of hip osteoarthritis among Chinese elderly in Beijing, China, compared with whites in the United States: the Beijing Osteoarthritis Study. Arthritis Rheum. 2002;46(7):1773-9.

15. Quintana JM, Arostegui I, Escobar A, Azkarate J, Goenaga JI, Lafuente I. Prevalence of knee and hip osteoarthritis and the appropriateness of joint replacement in an older population. Arch Intern Med. 2008;168(14):1576-84.

16. Kim C, Linsenmeyer KD, Vlad SC, et al. Prevalence of radiographic and symptomatic hip osteoarthritis in an urban United States community: the Framingham Osteoarthritis Study. Arthritis Rheumatol. 2014;66(11):3013-7.

17. Barbour KE, Lui LY, Nevitt MC, et al. Hip osteoarthritis and the risk of all-cause and disease-specific mortality in older women: a population-based cohort study. Arthritis Rheumatol. 2015;67(7):1798-805.

18. Jordan JM, Helmick CG, Renner JB, et al. Prevalence of hip symptoms and radiographic and symptomatic hip osteoarthritis in African Americans and Caucasians: the Johnston County Osteoarthritis Project. J Rheumatol. 2009;36(4):809-15.

19. Guilak F, Fermor B, Keefe FJ, et al. The role of biomechanics and inflammation in cartilage injury and repair. Clin Orthop Relat Res. 2004;423:17-26.

20. Setton LA, Mow C, Muller FJ, Pita JC, Howell DS. Mechanical behavior and biochemical composition of canine knee cartilage following periods of joint disuse and disuse with remobilization. Osteoarthr Cartil. 1997;5(1):1-16.

21. Eyre DR. Collagens and cartilage matrix homeostasis. Clin Orthop Relat Res. 2004;427:S118-22.

22. Smith RL, Carter DR, Schurman DJ. Pressure and shear differentially alter human articular chondrocyte metabolism: a review. Clin Orthop Relat Res. 2004;427:S89-95.

23. Lane Smith R, Trindade MC, Ikenoue T, et al. Effects of shear stress on articular chondrocyte metabolism. Biorheology. 2000;37(1-2):95-107.

24. Guilak F. Biomechanical factors in osteoarthritis. Best Pract Res Clin Rheumatol. 2011;25(6):815-23.

25. Li G, Yin J, Gao J, et al. Subchondral bone in osteoarthritis: insight into risk factors and microstructural changes. Arthritis Res Ther. 2013;15(6):223.

26. Mahjoub M, Berenbaum F, Houard X. Why subchondral bone in osteoarthritis? The importance of the cartilage bone interface in osteoarthritis. Osteoporos Int. 2012;23(Suppl 8):S841-6.

27. Sharma AR, Jagga S, Lee SS, Nam JS. Interplay between cartilage and subchondral bone contributing to pathogenesis of osteoarthritis. Int J Mol Sci. 2013;14(10):19805-30.

28. Henrotin Y, Pesesse L, Sanchez C. Subchondral bone and osteoarthritis: biological and cellular aspects. Osteoporos Int. 2012;23(Suppl 8):S847-51.

29. Lajeunesse D, Reboul P. Subchondral bone in osteoarthritis: a biologic link with articular cartilage leading to abnormal remodeling. Curr Opin Rheumatol. 2003;15(5):628-33.

30. Benito MJ, Veale DJ, FitzGerald O, van den Berg WB, Bresnihan B. Synovial tissue inflammation in early and late osteoarthritis. Ann Rheum Dis. 2005;64(9):1263-7.

31. Sandell LJ. Etiology of osteoarthritis: genetics and synovial joint development. Nat Rev Rheumatol. 2012;8(2):77-89.

32. Salter RB. Etiology, pathogenesis and possible prevention of congenital dislocation of the hip. Can Med Assoc J. 1968;98(20):933-45.

33. Weinstein SL. Natural history of congenital hip dislocation $(\mathrm{CDH})$ and hip dysplasia. Clin Orthop Relat Res. 1987;225:62-76.

34. Lloyd-Roberts GC. Osteoarthritis. Postgrad Med J. 1955;31(362):618-22.

35. Lloyd-Roberts GC. Osteoarthritis of the hip; a study of the clinical pathology. J Bone Jt Surg Br. 1955;37-b(1):8-47.

36. Harris WH. Etiology of osteoarthritis of the hip. Clin Orthop Relat Res. 1986;213:20-33.

37. Ganz R, Leunig M, Leunig-Ganz K, Harris WH. The etiology of osteoarthritis of the hip: an integrated mechanical concept. Clin Orthop Relat Res. 2008;466(2):264-72.

38. Ganz R, Parvizi J, Beck M, Leunig M, Nötzli H, Siebenrock K. Femoroacetabular impingement: a cause for osteoarthritis of the hip. Clin Orthop Relat Res. 2003;417:112-20.

39. Klaue K, Durnin CW, Ganz R. The acetabular rim syndrome. A clinical presentation of dysplasia of the hip. J Bone Jt Surg Br. 1991;73(3):423-9. 
40. Murray RO. The aetiology of primary osteoarthritis of the hip. Br J Radiol. 1965;38(455):810-24.

41. Lane NE, Lin P, Christiansen L, et al. Association of mild acetabular dysplasia with an increased risk of incident hip osteoarthritis in elderly white women: the study of osteoporotic fractures. Arthritis Rheum. 2000;43(2):400-4.

42. Tibor LM, Sink EL. Periacetabular osteotomy for hip preservation. Orthop Clin N Am. 2012;43(3):343-57.

43. Beck M, Kalhor M, Leunig M, Ganz R. Hip morphology influences the pattern of damage to the acetabular cartilage: femoroacetabular impingement as a cause of early osteoarthritis of the hip. J Bone Jt Surg Br. 2005;87(7):1012-8.

44. Bittersohl B, Steppacher S, Haamberg T, et al. Cartilage damage in femoroacetabular impingement (FAI): preliminary results on comparison of standard diagnostic vs delayed gadolinium-enhanced magnetic resonance imaging of cartilage (dGEMRIC). Osteoarthr Cartil. 2009;17(10):1297-306.

45. Ganz R, Gill TJ, Gautier E, Ganz K, Krugel N, Berlemann U. Surgical dislocation of the adult hip a technique with full access to the femoral head and acetabulum without the risk of avascular necrosis. J Bone Jt Surg Br. 2001;83(8):1119-24.

46. Laborie LB, Lehmann TG, Engesæter IØ, Engesæter LB, Rosendahl K. Clin Orthop Relat Res. 2013;471(7):2267-77

47. Dickenson E, Wall PD, Robinson B, et al. Prevalence of cam hip shape morphology: a systematic review. Osteoarthr Cartil. 2016;24:949-61.

48. Frank JM, Harris JD, Erickson BJ, et al. Prevalence of femoroacetabular impingement imaging findings in asymptomatic volunteers: a systematic review. Arthroscopy. 2015;31(6):1199-204.

49. Jung KA, Restrepo C, Hellman M, AbdelSalam H, Parvizi J, Morrison W. The prevalence of cam-type femoroacetabular deformity in asymptomatic adults. J Bone Jt Surg Br. 2011;93(10):1303-7.

50. Reichenbach S, Juni P, Werlen S, et al. Prevalence of cam-type deformity on hip magnetic resonance imaging in young males: a cross-sectional study. Arthritis Care Res (Hoboken). 2010;62(9):1319-27.

51. Wassilew GI, Heller MO, Diederichs G, Janz V, Wenzl M, Perka C. Standardized AP radiographs do not provide reliable diagnostic measures for the assessment of acetabular retroversion. J Orthop Res. 2012;30(9):1369-76.
52. Millis MB, Lewis CL, Schoenecker PL, Clohisy JC. Legg-Calve-Perthes disease and slipped capital femoral epiphysis: major developmental causes of femoroacetabular impingement. J Am Acad Orthop Surg. 2013;21(Suppl 1):S59-63.

53. Kuhns BD, Weber AE, Levy DM, Wuerz TH. The natural history of femoroacetabular impingement. Front Surg. 2015;2:58.

54. Amanatullah DF, Antkowiak T, Pillay K, et al. Femoroacetabular impingement: current concepts in diagnosis and treatment. Orthopedics. 2015;38(3):185-99.

55. Chakraverty JK, Sullivan C, Gan C, Narayanaswamy S, Kamath S. Cam and pincer femoroacetabular impingement: CT findings of features resembling femoroacetabular impingement in a young population without symptoms. AJR Am J Roentgenol. 2013;200(2):389-95.

56. Schmitz MR, Bittersohl B, Zaps D, Bomar JD, Pennock AT, Hosalkar HS. Spectrum of radiographic femoroacetabular impingement morphology in adolescents and young adults: an EOS-based double-cohort study. J Bone Jt Surg Am. 2013;95(13):e90.

57. Bouma H, Hogervorst T, Audenaert E, van Kampen $P$. Combining femoral and acetabular parameters in femoroacetabular impingement: the omega surface. Med Biol Eng Comput. 2015;53(11):1239-46.

58. Tannast M, Siebenrock KA, Anderson SE. Femoroacetabular impingement: radiographic diagnosis-what the radiologist should know. AJR Am J Roentgenol. 2007;188(6):1540-52.

59. Siebenrock KA, Schoeniger R, Ganz R. Anterior femoro-acetabular impingement due to acetabular retroversion. Treatment with periacetabular osteotomy. J Bone Jt Surg Am. 2003;85-a(2):278-86.

60. Ejnisman L, Philippon MJ, Lertwanich $\mathrm{P}$, et al. Relationship between femoral anteversion and findings in hips with femoroacetabular impingement. Orthopedics. 2013;36(3):e293-300.

61. Ng KC, Lamontagne M, Adamczyk AP, Rakhra KS, Beaule PE. Patient-specific anatomical and functional parameters provide new insights into the pathomechanism of cam FAI. Clin Orthop Relat Res. 2015;473(4):1289-96.

62. Bouma HW, Hogervorst T, Audenaert E, Krekel P, van Kampen PM. Can combining femoral and acetabular morphology parameters improve the characterization of femoroacetabular impingement? Clin Orthop Relat Res. 2015;473(4): 1396-403. 
63. Ito K, Minka MA 2nd, Leunig M, Werlen S, Ganz R. Femoroacetabular impingement and the cam-effect. A MRI-based quantitative anatomical study of the femoral head-neck offset. J Bone Jt Surg Br. 2001;83(2):171-6.

64. Reichenbach S, Leunig $M$, Werlen $S$, et al. Association between cam-type deformities and magnetic resonance imaging-detected structural hip damage: a cross-sectional study in young men. Arthritis Rheum. 2011;63(12):4023-30.

65. Stelzeneder D, Mamisch TC, Kress I, et al. Patterns of joint damage seen on MRI in early hip osteoarthritis due to structural hip deformities. Osteoarthr Cartil. 2012;20(7):661-9.

66. Sankar WN, Nevitt M, Parvizi J, Felson DT, Agricola R, Leunig M. Femoroacetabular impingement: defining the condition and its role in the pathophysiology of osteoarthritis. J Am Acad Orthop Surg. 2013;21(Suppl 1):S7-s15.

67. Kowalczuk M, Yeung M, Simunovic N, Ayeni OR. Does femoroacetabular impingement contribute to the development of hip osteoarthritis? A systematic review. Sports Med Arthrosc Rev. 2015;23(4):174-9.

68. Zeng WN, Wang FY, Chen C, et al. Investigation of association between hip morphology and prevalence of osteoarthritis. Sci Rep. 2016;6:23477.

69. Burstein D, Bashir A, Gray ML. MRI techniques in early stages of cartilage disease. Invest Radiol. 2000;35(10):622-38.

70. Kim YJ, Jaramillo D, Millis MB, Gray ML, Burstein D. Assessment of early osteoarthritis in hip dysplasia with delayed gadolinium-enhanced magnetic resonance imaging of cartilage. J Bone Jt Surg Am. 2003;85(10):1987-92.

71. Mamisch TC, Kain MS, Bittersohl B, et al. Delayed gadolinium-enhanced magnetic resonance imaging of cartilage (dGEMRIC) in femoacetabular impingement. J Orthop Res. 2011;29(9):1305-11.

72. Pollard TC, McNally EG, Wilson DC, et al. Localized cartilage assessment with three-dimensional dGEMRIC in asymptomatic hips with normal morphology and cam deformity. J Bone Jt Surg Am. 2010;92(15):2557-69.

73. Agricola R, Leyland KM, Bierma-Zeinstra SM, et al. Validation of statistical shape modelling to predict hip osteoarthritis in females: data from two prospective cohort studies (Cohort Hip and Cohort Knee and Chingford). Rheumatol (Oxford). 2015;54(11):2033-41.

74. Gregory JS, Waarsing JH, Day J, et al. Early identification of radiographic osteoarthritis of the hip using an active shape model to quantify changes in bone morphometric features: can hip shape tell us anything about the progression of osteoarthritis? Arthritis Rheum. 2007;56(11):3634-43.

75. Bardakos NV, Villar RN. Predictors of progression of osteoarthritis in femoroacetabular impingement: a radiological study with a minimum of ten years follow-up. J Bone Jt Surg Br. 2009;91(2):162-9.

76. Weinstein SL. Bristol-Myers Squibb/Zimmer award for distinguished achievement in orthopaedic research. Long-term follow-up of pediatric orthopaedic conditions. Natural history and outcomes of treatment. J Bone Jt Surg Am. 2000;82-a(7):980-90.

77. Enseki KR, Martin R, Kelly BT. Rehabilitation after arthroscopic decompression for femoroacetabular impingement. ClinSports Med. 2010;29(2):247-55 (viii).

78. Griffin KM. Rehabilitation of the hip. Clin Sports Med. 2001;20(4):837-50.

79. Stalzer S, Wahoff M, Scanlan M. Rehabilitation following hip arthroscopy. Clin Sports Med. 2006;25(2):337-57.

80. Wall PD, Fernandez M, Griffin DR, Foster NE. Nonoperative treatment for femoroacetabular impingement: a systematic review of the literature. PMR. 2013;5(5):418-26.

81. Ruhdorfer A, Wirth W, Hitzl W, Nevitt M, Eckstein F, Osteoarthritis Initiative I. Association of thigh muscle strength with knee symptoms and radiographic disease stage of osteoarthritis: data from the Osteoarthritis Initiative. Arthritis Care Res. 2014;66(9):1344-53.

82. van der Esch M, Holla JF, van der Leeden M, et al. Decrease of muscle strength is associated with increase of activity limitations in early knee osteoarthritis: 3-year results from the cohort hip and cohort knee study. Arch Phys Med Rehabil. 2014;95(10):1962-8.

83. Bennell K, Hinman RS, Wrigley TV, Creaby MW, Hodges P. Exercise and osteoarthritis: cause and effects. Compr Physiol. 2011;1(4):1943-2008.

84. Casartelli NC, Maffiuletti NA, Item-Glatthorn JF, et al. Hip muscle weakness in patients with symptomatic femoroacetabular impingement. Osteoarthr Cartil. 2011;19(7):816-21.

85. Diamond LE, Wrigley TV, Hinman RS, et al. Isometric and isokinetic hip strength and agonist/ antagonist ratios in symptomatic femoroacetabular impingement. J Sci Med Sport. 2016;19(9):696-701. 
86. Nepple JJ, Goljan P, Briggs KK, Garvey SE, Ryan M, Philippon MJ. Hip Strength deficits in patients with symptomatic femoroacetabular impingement and labral tears. Arthrosc J Arthrosc Relat Surg. 2015;31(11):2106-11.

87. Mantovani G, Lamontagne M, Dwyer K, Beaul' P. Muscular co-activation in subjects affected by femoroacetabular impingement. In: Bradshaw EJ, Burnett A, Hume PA, editors. 30th Annual International Conference of Biomechanics in Sports. Melbourne 2013. p. 68-71.

88. Loureiro A, Mills PM, Barrett RS. Muscle weakness in hip osteoarthritis: a systematic review. Arthritis Care Res. 2013;65(3):340-52.

89. Wong JM, Khan T, Jayadev CS, Khan W, Johnstone D. Anterior cruciate ligament rupture and osteoarthritis progression. Open orthop J. 2012;6:295-300.

90. Neumann G, Mendicuti AD, Zou KH, et al. Prevalence of labral tears and cartilage loss in patients with mechanical symptoms of the hip: evaluation using MR arthrography. Osteoarthr Cartil. 2007;15(8):909-17.

91. Lee AJ, Armour P, Thind D, Coates MH, Kang AC. The prevalence of acetabular labral tears and associated pathology in a young asymptomatic population. Bone Jt J. 2015;97-b(5):623-7.

92. Lage LA, Patel JV, Villar RN. The acetabular labral tear: an arthroscopic classification. Arthroscopy. 1996;12(3):269-72.

93. Wenger DE, Kendell KR, Miner MR, Trousdale RT. Acetabular labral tears rarely occur in the absence of bony abnormalities. Clin Orthop Relat Res. 2004;426:145-50.

94. Jawahar A, Vade A, Lomasney L, Okur G, Evans D, Subbaiah P. Clinical and surgical correlation of hip MR arthrographic findings in adolescents. Eur J Radiol. 2016;85(6):1192-8.

95. McCarthy J, Noble P, Aluisio FV, Schuck M, Wright J, Lee JA. Anatomy, pathologic features, and treatment of acetabular labral tears. Clin Orthop Relat Res. 2003;406:38-47.

96. Groh MM, Herrera J. A comprehensive review of hip labral tears. Curr Rev Musculoskelet Med. 2009;2(2):105-17.

97. Tan V, Seldes RM, Katz MA, Freedhand AM, Klimkiewicz JJ, Fitzgerald Jr RH. Contribution of acetabular labrum to articulating surface area and femoral head coverage in adult hip joints: an anatomic study in cadavera. Am J Orthop. 2001;30(11):809-12.
98. Seldes RM, Tan V, Hunt J, Katz M, Winiarsky R, Fitzgerald RH Jr. Anatomy, histologic features, and vascularity of the adult acetabular labrum. Clin Orthop Relat Res. 2001;382:232-40.

99. Hlavacek M. The influence of the acetabular labrum seal, intact articular superficial zone and synovial fluid thixotropy on squeeze-film lubrication of a spherical synovial joint. J Biomech. 2002;35(10):1325-35.

100. Crawford MJ, Dy CJ, Alexander JW, et al. The Frank Stinchfield Award: the biomechanics of the hip labrum and the stability of the hip. Clin Orthop Relat Res. 2007;2007(465):16-22.

101. McCarthy JC, Busconi B. The role of hip arthroscopy in the diagnosis and treatment of hip disease. Orthopedics. 1995;18(8):753-6.

102. McCarthy JC, Noble PC, Schuck MR, Wright J, J Lee, Otto E. Aufranc Award: the role of labral lesions to development of early degenerative hip disease. Clin Orthop Relat Res. 2001;393:25-37.

103. Felson DT, Lawrence RC, Dieppe PA, et al. Osteoarthritis: new insights. Part 1: the disease and its risk factors. Ann Intern Med. 2000;133(8):635-46.

104. Martin JA, Buckwalter JA. The role of chondrocyte senescence in the pathogenesis of osteoarthritis and in limiting cartilage repair. J Bone Jt Surg Am. 2003;85(A Suppl 2):106-10.

105. Vignon E, Arlot M, Patricot LM, Vignon G. The cell density of human femoral head cartilage. Clin Orthop Relat Res. 1976;121:303-8.

106. Buckwalter JA, Roughley PJ, Rosenberg LC. Age-related changes in cartilage proteoglycans: quantitative electron microscopic studies. Microsc Res Tech. 1994;28(5):398-408.

107. Loeser RF. Age-related changes in the musculoskeletal system and the development of osteoarthritis. Clin Geriatr Med. 2010;26(3):371-86.

108. Srikanth VK, Fryer JL, Zhai G, Winzenberg TM, Hosmer D, Jones G. A meta-analysis of sex differences prevalence, incidence and severity of osteoarthritis. Osteoarthr Cartil. 2005;13(9):769-81.

109. Jiang L, Rong J, Wang Y, et al. The relationship between body mass index and hip osteoarthritis: a systematic review and meta-analysis. Jt Bone Spine. 2011;78(2):150-5.

110. Reyes C, Leyland KM, Peat G, Cooper C, Arden NK, Prieto-Alhambra D. Association between overweight and obesity and risk of clinically diagnosed knee, hip, and hand osteoarthritis: a 
population-based cohort study. Arthritis Rheumatol. 2016;68(8):1869-75.

111. Grotle M, Hagen KB, Natvig B, Dahl FA, Kvien TK. Obesity and osteoarthritis in knee, hip and/or hand: an epidemiological study in the general population with 10 years follow-up. BMC Musculoskelet Disord. 2008;9:132.

112. Hartz AJ, Fischer ME, Bril G, et al. The association of obesity with joint pain and osteoarthritis in the HANES data. J Chron Dis. 1986;39(4):311-9.

113. Vuolteenaho K, Koskinen A, Kukkonen M, et al. Leptin enhances synthesis of proinflammatory mediators in human osteoarthritic cartilagemediator role of NO in leptin-induced PGE2, IL-6, and IL-8 production. Mediators Inflamm. 2009;2009:345838.

114. Carman WJ, Sowers M, Hawthorne VM, Weissfeld LA. Obesity as a risk factor for osteoarthritis of the hand and wrist: a prospective study. Am J Epidemiol. 1994;139(2):119-29.

115. MacGregor AJ, Antoniades L, Matson M, Andrew T, Spector TD. The genetic contribution to radiographic hip osteoarthritis in women: results of a classic twin study. Arthritis Rheum. 2000;43(11):2410-6.

116. Pelt CE, Erickson JA, Peters CL, Anderson MB, Cannon-Albright L. A heritable predisposition to osteoarthritis of the hip. J Arthroplasty. 2015;30(9 Suppl):125-9.

117. Zengini E, Finan C, Wilkinson JM. The genetic epidemiological landscape of hip and knee osteoarthritis: where are we now and where are we going? J Rheumatol. 2016;43(2):260-6.

118. Lau EM, Lin F, Lam D, Silman A, Croft P. Hip osteoarthritis and dysplasia in Chinese men. Ann Rheum Dis. 1995;54(12):965-9.

119. Yoshimura N, Campbell L, Hashimoto T, et al. Acetabular dysplasia and hip osteoarthritis in Britain and Japan. Br J Rheumatol. 1998;37(11):1193-7.

120. Dudda M, Kim YJ, Zhang Y, et al. Morphologic differences between the hips of Chinese women and white women: could they account for the ethnic difference in the prevalence of hip osteoarthritis? Arthritis Rheum. 2011;63(10):2992-9.

121. Harris EC, Coggon D. HIP osteoarthritis and work. Best Pract Res Clin Rheumatol. 2015;29(3):462-82.

122. Sulsky SI, Carlton L, Bochmann F, et al. Epidemiological evidence for work load as a risk factor for osteoarthritis of the hip: a systematic review. PLoS One. 2012;7(2):e31521.

123. Bennell K, Hunter DJ, Vicenzino B. Long-term effects of sport: preventing and managing $\mathrm{OA}$ in the athlete. Nat Rev Rheumatol. 2012;8(12):747-52.

124. Gouttebarge V, Inklaar H, Backx F, Kerkhoffs G. Prevalence of osteoarthritis in former elite athletes: a systematic overview of the recent literature. Rheumatol Int. 2015;35(3):405-18.

125. Packer JD, Safran MR. The etiology of primary femoroacetabular impingement: genetics or acquired deformity? J Hip Preserv Surg. 2015;2(3):249-57.

126. Agricola R, Bessems JH, Ginai AZ, et al. The development of Cam-type deformity in adolescent and young male soccer players. Am J Sports Med. 2012;40(5):1099-106.

127. Kapron AL, Anderson AE, Aoki SK, et al. Radiographic prevalence of femoroacetabular impingement in collegiate football players: AAOS Exhibit Selection. J Bone Jt Surg Am. 2011;93(19):e111(1-10).

128. Siebenrock KA, Ferner F, Noble PC, Santore RF, Werlen S, Mamisch TC. The cam-type deformity of the proximal femur arises in childhood in response to vigorous sporting activity. Clin Orthop Relat Res. 2011;469(11):3229-40.

129. Peterson RO, Vucetich JA, Fenton G, Drummer TD, Larsen CS. Ecology of arthritis. Ecol Lett. 2010;13(9):1124-8.

130. Bergink AP, Zillikens MC, Van Leeuwen JP, Hofman A, Uitterlinden AG, van Meurs JB. 25-Hydroxyvitamin $\mathrm{D}$ and osteoarthritis: a meta-analysis including new data. Semin Arthritis Rheum. 2016;45(5):539-46.

131. McAlindon TE, Felson DT, Zhang Y, et al. Relation of dietary intake and serum levels of vitamin D to progression of osteoarthritis of the knee among participants in the Framingham Study. Ann Intern Med. 1996;125(5):353-9.

132. Lane NE, Gore LR, Cummings SR, et al. Serum vitamin D levels and incident changes of radiographic hip osteoarthritis: a longitudinal study. Study of Osteoporotic Fractures Research Group. Arthritis Rheum. 1999;42(5):854-60.

133. Misra D, Booth SL, Tolstykh I, et al. Vitamin K deficiency is associated with incident knee osteoarthritis. Am J Med. 2013;126(3):243-8.

134. Neogi T, Booth SL, Zhang YQ, et al. Low vitamin $\mathrm{K}$ status is associated with osteoarthritis in the hand and knee. Arthritis Rheum. 2006;54(4):1255-61. 
135. Shea MK, Kritchevsky SB, Hsu FC, et al. The association between vitamin $\mathrm{K}$ status and knee osteoarthritis features in older adults: The Health, Aging and Body Composition Study. Osteoarthr Cartil. 2015;23(3):370-8.

136. Neogi T, Felson DT, Sarno R, Booth SL. Vitamin K in hand osteoarthritis: results from a randomised clinical trial. Ann Rheum Dis. 2008;67(11):1570-3.

137. McAlindon TE, Jacques $\mathrm{P}$, Zhang $\mathrm{Y}$, et al. Do antioxidant micronutrients protect against the development and progression of knee osteoarthritis? Arthritis Rheum. 1996;39(4):648-56.

138. Peregoy J, Wilder FV. The effects of vitamin C supplementation on incident and progressive knee osteoarthritis: a longitudinal study. Public Health Nutr. 2011;14(4):709-15.

139. Li H, Zeng C, Wei J, et al. Associations between dietary antioxidants intake and radiographic knee osteoarthritis. Clin Rheumatol. 2016;35(6):1585-92.

140. Montgomery SR, Ngo SS, Hobson T, et al. Trends and demographics in hip arthroscopy in the United States. Arthrosc J Arthrosc Relat Surg. 2013;29(4):661-5.

141. Wall PD, Brown JS, Parsons N, Buchbinder R, Costa ML, Griffin D. Surgery for treating hip impingement (femoroacetabular impingement). Cochrane Database Syst Rev. 2014;9:CD010796.

142. Kemp JL, MacDonald D, Collins NJ, Hatton AL, Crossley KM. Hip arthroscopy in the setting of hip osteoarthritis: systematic review of outcomes and progression to hip arthroplasty. Clin Orthop Relat Res. 2015;473(3):1055-73.

143. Peters CL. Mild to moderate hip OA: joint preservation or total hip arthroplasty? J Arthroplasty. 2015;30(7):1109-12.

144. Nguyen C, Lefevre-Colau MM, Poiraudeau S, Rannou F. Rehabilitation (exercise and strength training) and osteoarthritis: a critical narrative review. Ann Phys Rehabil Med. 2016;59(3):190-5.

145. McAlindon TE, Bannuru RR, Sullivan MC, et al. OARSI guidelines for the non-surgical management of knee osteoarthritis. Osteoarthr Cartil. 2014;22(3):363-88.

146. Bennell K. Physiotherapy management of hip osteoarthritis. J Physiother. 2013;59(3):145-57.

147. Paans N, van den Akker-Scheek I, Dilling RG, et al. Effect of exercise and weight loss in people who have hip osteoarthritis and are overweight or obese: a prospective cohort study. Phys Ther. 2013;93(2):137-46.

148. Fransen M, McConnell S, Hernandez-Molina G, Reichenbach S. Exercise for osteoarthritis of the hip. Cochrane Database Syst Rev. 2014;4:Cd007912.

149. Bennell KL, Buchbinder R, Hinman RS. Physical therapies in the management of osteoarthritis: current state of the evidence. Curr Opin Rheumatol. 2015;27(3):304-11.

150. Fransen M, McConnell S, Harmer AR, Van der Esch M, Simic M, Bennell KL. Exercise for osteoarthritis of the knee. Cochrane Database Syst Rev. 2015;1:Cd004376.

151. Svege I, Nordsletten L, Fernandes L, Risberg MA. Exercise therapy may postpone total hip replacement surgery in patients with hip osteoarthritis: a long-term follow-up of a randomised trial. Ann Rheum Dis. 2015;74(1):164-9.

152. Tan SS, Teirlinck CH, Dekker J, et al. Cost-utility of exercise therapy in patients with hip osteoarthritis in primary care. Osteoarthr Cartil. 2016;24(4):581-8.

153. Gay C, Chabaud A, Guilley E, Coudeyre E. Educating patients about the benefits of physical activity and exercise for their hip and knee osteoarthritis. Systematic literature review. Ann Phys Rehabil Med. 2016;59(3):174-83.

154. Wang Q, Wang TT, Qi XF, et al. Manual therapy for hip osteoarthritis: a systematic review and meta-analysis. Pain Phys. 2015;18(6):E1005-20.

155. Beumer L, Wong J, Warden SJ, Kemp JL, Foster P, Crossley KM. Effects of exercise and manual therapy on pain associated with hip osteoarthritis: a systematic review and meta-analysis. Br J Sports Med. 2016;50(8):458-63.

156. Bennell KL, Egerton T, Martin J, et al. Effect of physical therapy on pain and function in patients with hip osteoarthritis: a randomized clinical trial. JAMA. 2014;311(19):1987-97.

157. Nerot A, Nicholls $M$. The effect on gait biomechanics of a new orthosis for hip OA. Osteoarthr Cartil. 2014;22:S114.

158. Nerot A, Nicholls M. The effect of a new hip OA brace on the sit-to-stand maneuver. Osteoarthr Cartil. 2014;22:S99.

159. Sato T, Yamaji T, Inose $H$, et al. Effect of a modified S-form hip brace, WISH type, for patients with painful osteoarthritis of the hip: a role in daily 
walking as a hip muscle exercise. Rheumatol Int. 2008;28(5):419-28.

160. Sato E, Sato T, Yamaji T, Watanabe H. Effect of the WISH-type hip brace on functional mobility in patients with osteoarthritis of the hip: evaluation using the Timed Up \& Go Test. Prosthet Orthot Int. 2012;36(1):25-32.

161. Gelber AC. Conventional medical therapy for osteoarthritis: current state of the evidence. Curr Opin Rheumatol. 2015;27(3):312-7.

162. Hunter DJ. Pharmacologic therapy for osteoarthritis-the era of disease modification. Nat Rev Rheumatol. 2011;7(1):13-22.

163. Percope de Andrade MA, Campos TV, Abreu ESGM. Supplementary methods in the nonsurgical treatment of osteoarthritis. Arthroscopy. 2015;31(4):785-92.

164. Hunter DJ, Hellio Le Graverand-Gastineau MP. How close are we to having structure-modifying drugs available? Med Clin N Am. 2009;93(1):223-34 xii.

165. Machado GC, Maher CG, Ferreira PH, et al. Efficacy and safety of paracetamol for spinal pain and osteoarthritis: systematic review and meta-analysis of randomised placebo controlled trials. BMJ. 2015;350:h1225.

166. da Costa BR, Reichenbach S, Keller N, et al. Effectiveness of non-steroidal anti-inflammatory drugs for the treatment of pain in knee and hip osteoarthritis: a network meta-analysis. Lancet. 2016;387(10033):2093-105.

167. Derry S, Conaghan P, Da Silva JA, Wiffen PJ, Moore RA. Topical NSAIDs for chronic musculoskeletal pain in adults. Cochrane Database Syst Rev. 2016;4:Cd007400.

168. Chappell AS, Desaiah D, Liu-Seifert H, et al. A double-blind, randomized, placebo-controlled study of the efficacy and safety of duloxetine for the treatment of chronic pain due to osteoarthritis of the knee. Pain Pract. 2011;11(1):33-41.

169. Chappell AS, Ossanna MJ, Liu-Seifert $H$, et al. Duloxetine, a centrally acting analgesic, in the treatment of patients with osteoarthritis knee pain: a 13-week, randomized, placebo-controlled trial. Pain. 2009;146(3):253-60.

170. Gahimer J, Wernicke J, Yalcin I, Ossanna MJ, Wulster-Radcliffe M, Viktrup L. A retrospective pooled analysis of duloxetine safety in 23,983 subjects. Curr Med Res Opin. 2007;23(1):175-84.

171. Cepeda MS, Camargo F, Zea C, Valencia L. Tramadol for osteoarthritis: a systematic review and metaanalysis. J Rheumatol. 2007;34(3):543-55.
172. da Costa BR, Nuesch E, Kasteler R, et al. Oral or transdermal opioids for osteoarthritis of the knee or hip. Cochrane Database Syst Rev. 2014;9:Cd003115.

173. McCabe PS, Maricar N, Parkes MJ, Felson DT, O'Neill TW. The efficacy of intra-articular steroids in hip osteoarthritis: a systematic review. Osteoarthr Cartil. 2016;24(9):1509-17.

174. Rivera F. Single intra-articular injection of high molecular weight hyaluronic acid for hip osteoarthritis. J Orthop Traumatol. 2016;17(1):21-6.

175. Qvistgaard E, Christensen R, Torp-Pedersen S, Bliddal H. Intra-articular treatment of hip osteoarthritis: a randomized trial of hyaluronic acid, corticosteroid, and isotonic saline. Osteoarthr Cartil. 2006;14(2):163-70.

176. Atchia I, Kane D, Reed MR, Isaacs JD, Birrell F. Efficacy of a single ultrasound-guided injection for the treatment of hip osteoarthritis. Ann Rheum Dis. 2011;70(1):110-6.

177. Migliore A, Granata M, Tormenta S, et al. Hip viscosupplementation under ultra-sound guidance riduces NSAID consumption in symptomatic hip osteoarthritis patients in a long follow-up. Data from Italian registry. Eur Rev Med Pharmacol Sci. 2011;15(1):25-34.

178. Lieberman JR, Engstrom SM, Solovyova O, Au C, Grady JJ. Is intra-articular hyaluronic acid effective in treating osteoarthritis of the hip joint? J Arthroplasty. 2015;30(3):507-11.

179. Chandrasekaran S, Lodhia P, Suarez-Ahedo C, Vemula SP, Martin TJ, Domb BG. Symposium: evidence for the use of intra-articular cortisone or hyaluronic acid injection in the hip. J Hip Preserv Surg. 2016;3(1):5-15.

180. Ornetti P, Nourissat G, Berenbaum F, Sellam J, Richette P, Chevalier X. Does platelet-rich plasma have a role in the treatment of osteoarthritis? Jt Bone Spine. 2016;83(1):31-6.

181. Battaglia M, Guaraldi F, Vannini F, et al. Efficacy of ultrasound-guided intra-articular injections of platelet-rich plasma versus hyaluronic acid for hip osteoarthritis. Orthopedics. 2013;36(12): e1501-8.

182. Dallari D, Stagni C, Rani N, et al. Ultrasound-guided injection of platelet-rich plasma and hyaluronic acid, separately and in combination, for hip osteoarthritis: a randomized controlled study. Am J Sports Med. 2016;44(3):664-71.

183. Pivec R, Johnson AJ, Mears SC, Mont MA. Hip arthroplasty. Lancet. 2012;380(9855):1768-77. 
184. Daigle ME, Weinstein AM, Katz JN, Losina E. The cost-effectiveness of total joint arthroplasty: a systematic review of published literature. Best Pract Res Clin Rheumatol. 2012;26(5):649-58.

185. Kurtz S, Ong K, Lau E, Mowat F, Halpern M. Projections of primary and revision hip and knee arthroplasty in the United States from 2005 to 2030. J Bone Jt Surg Am. 2007;89(4):780-5.

186. Vergara I, Bilbao A, Gonzalez N, Escobar A, Quintana JM. Factors and consequences of waiting times for total hip arthroplasty. Clin Orthop Relat Res. 2011;469(5):1413-20.
187. Marshall DA, Pykerman K, Werle J, et al. Hip resurfacing versus total hip arthroplasty: a systematic review comparing standardized outcomes. Clin Orthop Relat Res. 2014;472(7):2217-30.

188. Sehatzadeh S, Kaulback K, Levin L. Metal-on-metal hip resurfacing arthroplasty: an analysis of safety and revision rates. Ont Health Technol Assess Ser. 2012;12(19):1-63.

189. Matharu GS, Pandit HG, Murray DW, Treacy RB. The future role of metal-on-metal hip resurfacing. Int Orthop. 2015;39(10):2031-6. 